\title{
Light Stress Is Not Effective to Enhanced Crassulacean Acid Metabolism
}

\author{
Andrzej Kornas ${ }^{\mathrm{a}}$, Zbigniew Miszalskia $^{\mathrm{a}, \mathrm{b}, *}$, Ewa Surówka $^{\mathrm{b}}$, Elke Fischer-Schliebs $^{\mathrm{c}}$, \\ and Ulrich Lüttge \\ a Institute of Biology, Pedagogical University, ul. Podbrzezie 3, 31-054 Krakow, Poland \\ b Institute of Plant Physiology, Polish Academy of Sciences, ul. Niezapominajek 21, 30-239 \\ Krakow, Poland. Fax: +48-12-4251844. E-mail: miszalski@ifr-pan.krakow.pl \\ c Institute of Botany, Darmstadt University of Technology, Schnittspahnstrasse 3-5, \\ D-64287 Darmstadt, Germany \\ * Author for correspondence and reprint requests \\ Z. Naturforsch. 65c, 79-86 (2010); received September 10/October 21, 2009
}

Clusia minor L., a $\mathrm{C}_{3}$-CAM intermediate, and Clusia multiflora $\mathrm{H}$. B. K., a $\mathrm{C}_{3}$ obligate, present two physiotypes of a similar morphotype occurring sympatrically in the field. Both species, exposed 2 days to high light, show similar responses to this kind of stress: (i) the level of xanthophyll pigments in tested plants during the daycourse adapts to stress, (ii) the levels of antheraxanthin and zeaxanthin clearly increase during the afternoon showing increased de-epoxidation, (iii) the changes in the xanthophyll cycle are similar. Exposure to high light increases the malate levels in $C$. minor during the afternoon while decreases the day/night changes of the malate levels, and hence the Crassulacean Acid Metabolism (CAM) expression. It can be concluded that strong light applied as a single stress factor to well-watered plants is not effective in strengthing the CAM metabolism in a $\mathrm{C}_{3}$-CAM intermediate plant but rather suppresses the CAM activity despite exposure to high light energy. It is suggested that, when water supply is not limiting and other stresses do not prevail, $\mathrm{C}_{3}$ allows to use up the citrate pool, especially in the afternoon and enables a superior daily photon utilization.

Key words: Oxidative Stress, Xanthophyll Cycle, Clusia

\section{Introduction}

In plants several reactive oxygen species (ROS) such as: $\mathrm{O}_{2}^{-\bullet}, \mathrm{HO}^{-}, \mathrm{H}_{2} \mathrm{O}_{2}$, are generated predominantly during the light period in chloroplasts and can cause photooxidative damage (Foyer and Noctor, 2003). ROS affect the redox status of the cells and subsequently have an impact on the regulation of many cellular processes (Inzé and van Montagu, 1995; Bartosz, 1997; Halliwell and Gutteridge, 1999; Mittler, 2002). There are several systems to protect cells from an excess of ROS compounds. It was also shown that due to stress conditions ROS levels increase and plants adapt their levels of low molecular antioxidants (glutathione, ascorbic acid, carotenoids) and the activities of antioxidative enzymes (superoxide dismutase,

Abbreviations: A, antheraxanthin; EPS, epoxidation state of the xanthophyll cycle pigments; PPFD, photosynthetic photon flux density; ROS, reactive oxygen species; V, violaxanthin; Z, zeaxanthin. catalase, peroxidase, glutathione reductase) (Scandalios, 1993; Adams and Demmig-Adams, 1994; Dat et al., 2000). Carotenoids localized in chloroplasts serve as light-harvesting pigments and also play an important role in protecting the photosynthetic apparatus against photooxidative damage (Siefermann-Harms, 1987). To the most important carotenoids belong: $\beta$-carotene and the xanthophylls [neoxanthin, lutein, violaxanthin $(\mathrm{V})$, antheraxanthin (A), and zeaxanthin (Z)]. V, $\mathrm{A}$ and $\mathrm{Z}$ are pigments participating in the xanthophyll cycle, the reversible cyclic reactions dissipating excess light energy as heat. In plants equipped with the xanthophyll cycle during a change from low light (that does not saturate photosynthesis) to excess light (when more light is absorbed than it can be utilized by photosynthesis), $\mathrm{V}$ is reversibly converted to $\mathrm{Z}$. Z constitutes part of the xanthophyll cycle where reversible cyclic reactions dissipate excess light energy as heat. A correlation between the conversion state of the xanthophyll cycle pigments and the level of thermal en- 
ergy dissipation was observed in a wide range of different plant species for a given degree of light stress independently of species (Demmig-Adams and Adams, 1996). The degree to which $\mathrm{V}$ is deepoxidized varies widely as a result of variation in the level of $\mathrm{V}+\mathrm{A}+\mathrm{Z}$ as well as the degree of their interconversion (Adams and Demmig-Adams, 1992). However, non-photochemical quenching (NPQ) does not correlate with the amount of $\mathrm{Z}$ (Johnson et al., 2008) indicating that control of the xanthophyll cycle pool size is not necessary to optimize the kinetics of NPQ.

In CAM (Crassulacean acid metabolism) plants carbon fixed during the night can be accumulated as malate, citrate or isocitrate and their decarboxylation during the following day may help alleviating photoinhibition (Franco et al., 1992; Borland et al., 1996; Chen et al., 2002). Changes in the mode of photosynthetic metabolism are accompanied by differences in regulation of stomatal opening.

In some plants during $\mathrm{C}_{3}$-CAM transitions strong changes in the antioxidant system do occur (Castillo, 1996; Miszalski et al., 1998; Niewiadomska et al., 1999; Slesak et al., 2002). However, we do not know the exact mechanism of metabolic changes. Plants performing CAM show very strong diurnal rhythms in the activity of some antioxidants (Niewiadomska et al., 1999, 2004; Slesak et al., 2002; Niewiadomska and Borland, 2008; Kornas et al., 2009). We know that free radicals are involved in CAM induction, but it is not clear whether they are responsible for CAM induction per se and/or diurnal CAM regulation. We know that in Mesembryanthemum crystallinum, a $\mathrm{C}_{3}$-CAM intermediate plant, light intensity above some threshold is needed for CAM induction (Miszalski et al., 2001), and according to Broetto et al. (2002) strong light alone can induce CAM. However, according to other publications light even at the level of $1500 \mu \mathrm{mol} \mathrm{m}^{-2} \mathrm{~s}^{-1}$ does not result in metabolic transformation (Barker et al., 2004).

In the family of Clusiaceae there are several $\mathrm{C}_{3}$-CAM intermediate species (Herzog et al., 1999; Lüttge, 2000, 2004). Among the $\mathrm{C}_{3}$-CAM plants Clusia minor is the best studied species which can switch very rapidly (within 1 to 2 days) and reversibly from $\mathrm{C}_{3}$ photosynthesis to CAM in response to temperature, high light, and drought stress (Borland et al., 1996; Herzog et al., 1999; Mattos et al., 1999; Dodd et al., 2002). As in other experiments (Herzog et al., 1999; Lüttge, 1999, $2000,2007)$ for comparisons aiming to illuminate the functioning of CAM, the putative obligate $\mathrm{C}_{3}$ plant C. multiflora was used. Both species are capable of rapid accumulation of $\mathrm{Z}$ for acute photoprotection following high light exposure (Herzog et al., 1999), however, other pigments of the violaxanthin cycle were not analyzed.

Firstly, in the present study it should be found out whether an increased light level can affect CAM - day/night fluctuations. Secondly, does light stress cause similar changes in the xanthophyll cycle activity of different plant species representing different modes of photosynthetical metabolism, i.e. $\mathrm{CAM}$ and $\mathrm{C}_{3}$, respectively?

\section{Material and Methods}

\section{Plants}

Experimental plants of $C$. minor L. and $C$. multiflora H. B. K. originated from cuttings of the Clusia plants collection of Botanical Garden of Darmstadt University of Technology (TUD), Germany. After a 2-month rooting period plants were repotted in plastic containers with a defined amount of soil (Fruhsdorfer Einheitserde LD 80, 0.231 per plant) and were grown under a natural photoperiod at low light intensity [PPFD (photosynthetic photon flux density) $=50-100 \mu \mathrm{mol}$ $\left.\mathrm{m}^{-2} \mathrm{~s}^{-1} ; \lambda=400-700 \mathrm{~nm}\right]$ in November. Cuttings for propagation were made about 6 months prior to experiments. Thereafter plants were transferred to a semi-controlled environment cabinet in the phytotron of the TUD and exposed to the following conditions: about $70 \% \mathrm{RH}$ (relative humidity), day/night temperatures at $26^{\circ} \mathrm{C} / 18{ }^{\circ} \mathrm{C}$, and a $12 \mathrm{~h} / 12 \mathrm{~h}$ photoperiod (intermediate PPFD of $200 \mu \mathrm{mol} \mathrm{m}^{-2} \mathrm{~s}^{-1}$ at the plane of leaves). Plants were watered and fertilized regularly (Hakaphos mineral nutrients, Compo, Münster, Germany). After $8 \mathrm{~d}$ of adaptation all parameters were measured as the control (day 0) and thereafter plants were exposed for $2 \mathrm{~d}$ to high light (HL) (PPFD = $\left.650-740 \mu \mathrm{mol} \mathrm{m}^{-2} \mathrm{~s}^{-1}\right)$ for $12 \mathrm{~h}$ per day. All measurements were performed during the 2 nd day of stress application (3rd day of experiments). The irradiance was measured using a LiCor quantum sensor (model Li-190SB, Campbell Scientific, Logan, UT, USA) 


\section{Stomatal aperture}

The stomatal resistance was measured using a Delta-T Devices Porometer MK III (Burwell, Cambridge, UK), which was calibrated according to the manufacturer's instructions.

\section{Malate and citrate levels}

Prior to the cell sap collection leaf discs were heated for $3 \mathrm{~min}$ at $100^{\circ} \mathrm{C}$. Malate and citrate levels were determined in cell sap obtained after 3 min of centrifugation (at $12000 \times \mathrm{g}$ ) of homogenized leaf discs. For determination of the malate level, malate dehydrogenase and glutamate oxaloacetate transaminase were used according to Möllering (1974). For determination of the citrate level, citrate lyase, malate dehydrogenase and lactate dehydrogenase were used according to Möllering (1985).

\section{Composition of carotenoids and EPS value calculations}

The carotenoid composition of leaves was determined by HPLC. Two discs $(0.5 \mathrm{~cm}$ i.d.) were cut out of the leaves and were homogenized in $2 \mathrm{ml}$ of solvent A (acetonitrile/methanol/water, 72:8:1) in a mortar under dim light. The extract was transferred to an Eppendorf tube, centrifuged at $10000 \times \mathrm{g}$ for $5 \mathrm{~min}$, and the supernatant was directly injected in a HPLC apparatus [C18 reverse-phase column, 250 × $4 \mathrm{~mm}, 5 \mu \mathrm{m}$ (Tracer Analytica, Barcelona, Spain)]. All samples were run isocratically in solvent $\mathrm{A}$ at the flow rate of $1 \mathrm{ml} / \mathrm{min}$ for $15 \mathrm{~min}$, to separate the xanthophylls. The solvent was changed afterwards to solvent B (methanol/ethyl acetate, 34:16) and a flow rate of $2 \mathrm{ml} / \mathrm{min}$ for $35 \mathrm{~min}$ to elute chlorophylls and $\beta$-carotene. The detection wavelength was $440 \mathrm{~nm}$ and the injection volume $100 \mu \mathrm{l}$. The relative contents of the carotenoids were calculated from the area of the corresponding peaks. The EPS value (epoxidation state of the xanthophyll cycle pigments $),(\mathrm{V}+0.5 \mathrm{~A}) /(\mathrm{V}+\mathrm{A}+\mathrm{Z})$, where $\mathrm{V}, \mathrm{A}$ and $\mathrm{Z}$ are the contents of the corresponding compounds, was calculated according to Thayer and Björkman (1990).

\section{Statistics}

Errors are given as standard deviations (SD). Significance of differences between treatments was determined with T-test.

\section{Results}

The shape of the daily course of stomatal resistance measured during the 2 nd day of exposure to high PPFD for $C$. multiflora (obligate $\mathrm{C}_{3}$ plant) and $C$. minor $\left(\mathrm{C}_{3}-\mathrm{CAM}\right.$ intermediate plant) was similar from 16:00 to midnight (Fig. 1A). Measurements of $\mathrm{V}, \mathrm{A}$ and $\mathrm{Z}$ contents in both tested species cultivated at low light (day 0 ) showed no distinct daily fluctuations (before noon and afternoon hours) in both $\mathrm{C}_{3}$ and $\mathrm{C}_{3}$-CAM intermediate plants (Fig. 2). In both Clusia plants during the 2nd day of exposure to HL also no clear changes in the amount of $\mathrm{V}$ were visible (Fig. 2A), while the contents of $\mathrm{A}$ and $\mathrm{Z}$ increased during the afternoon (16:00-20:00); however, due to the large $\mathrm{SD}$, only for $C$. minor the differences are statisti-
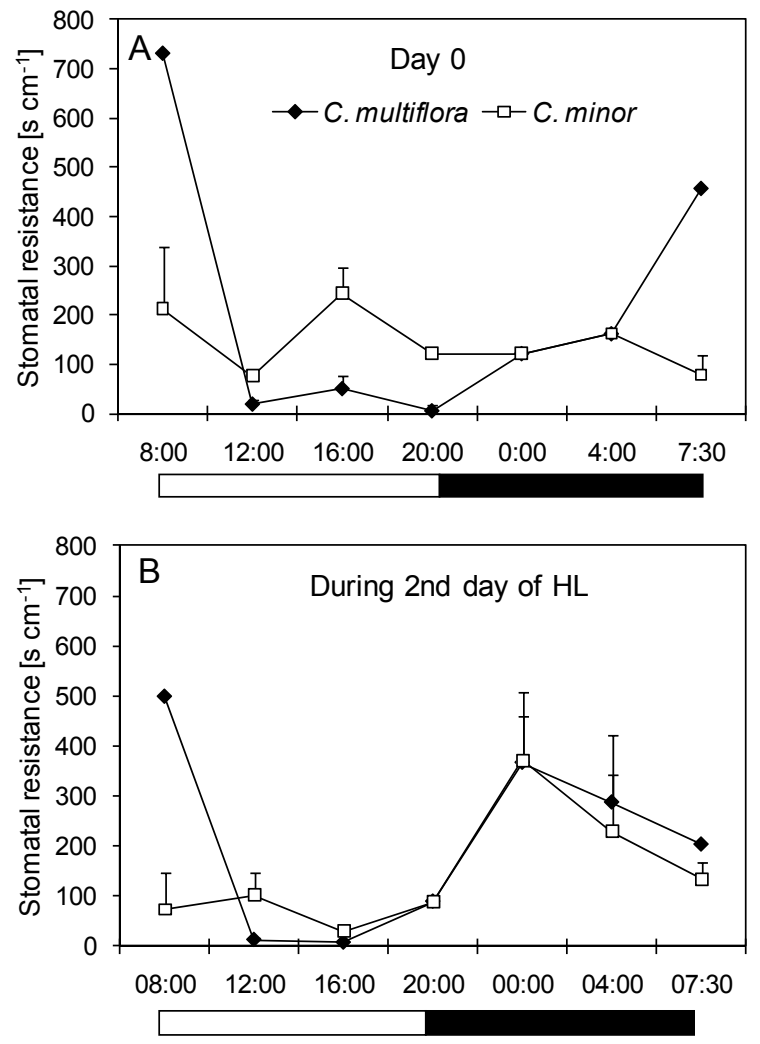

Fig. 1. Daily time course of the stomatal resistance in leaves of Clusia minor and Clusia multiflora (A) growing at low light (day 0) and (B) during the 2nd day of stress application of high light (HL, 650-740 $\mu \mathrm{mol}$ $\mathrm{m}^{-2} \mathrm{~s}^{-1}$ ) under well-watered conditions. Data represent mean values \pm SD $(n=10)$. Open and closed bars represent light and dark periods, respectively. 
cally significant ( $p=0.01)$ (Fig. $2 \mathrm{~B}$ and C). The EPS values were comparable during all periods in both tested plants (Fig. 3). The malate level in $C$. minor was higher than in C. multiflora. Its decrease in $C$. minor in the afternoon on day 0 was statistically highly significant $(p=0.001)$ indicating performance of CAM in the absence of light
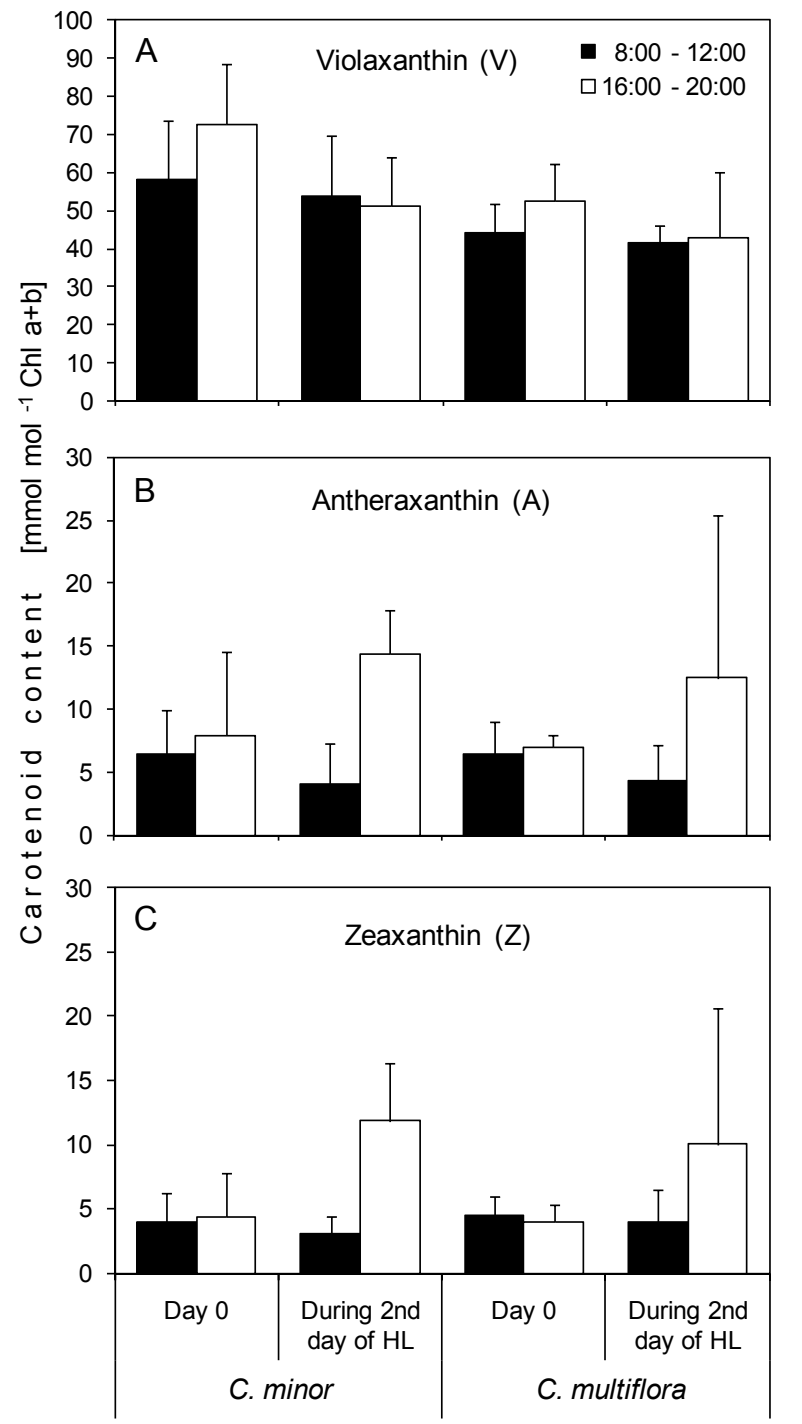

Fig. 2. Daily time course of the levels of the xanthophyll cycle pigments: (A) violaxanthin, (B) antheraxanthin, and (C) zeaxanthin in leaves of Clusia minor and Clusia multiflora growing at low light (day 0) and during the 2nd day of stress application of high light (HL, $\left.650-740 \mu \mathrm{mol} \mathrm{m} \mathrm{m}^{-2} \mathrm{~s}^{-1}\right)$ under well-watered conditions. Data represent mean values $\pm \mathrm{SD}(n=3)$. stress. On the 2nd day of HL stress the decline of the malate level was not insignificant anymore $(p=0.02)$. In both species only small significant fluctuations in the citrate levels, when growing at low light (day 0 ) and during the 2nd day of exposure to HL, were observed. In C. multiflora on the 2nd day of HL stress the decrease of citrate pool was stated during the morning $(p=0.02)$ and afternoon $(p=0.006)$ hours, when compared to day 0 (Fig. 4).

\section{Discussion}

In our experiments we applied HL stress (approx. $650-740 \mu \mathrm{mol} \mathrm{m}^{-2} \mathrm{~s}^{-1}$ ), without causing additional stresses like drought, and kept the plants well watered. During the 2nd day of HL stress in $C$. minor $\left(\mathrm{C}_{3}\right.$-CAM intermediate $)$ a reduction of stomatal resistance, when measured during afternoon hours, was observed as compared to day 0 (Fig. 1). This could be an indication that CAM was not induced (which would lead to an increase in resistance). In both $C$. minor and $C$. multiflora $\left(\mathrm{C}_{3}\right.$ obligate $)$ exposed to $\mathrm{HL}$ a strong increase in stomatal resistance during the night was observed, thus their sensitivity was similar. This can be regarded as another indication that HL was

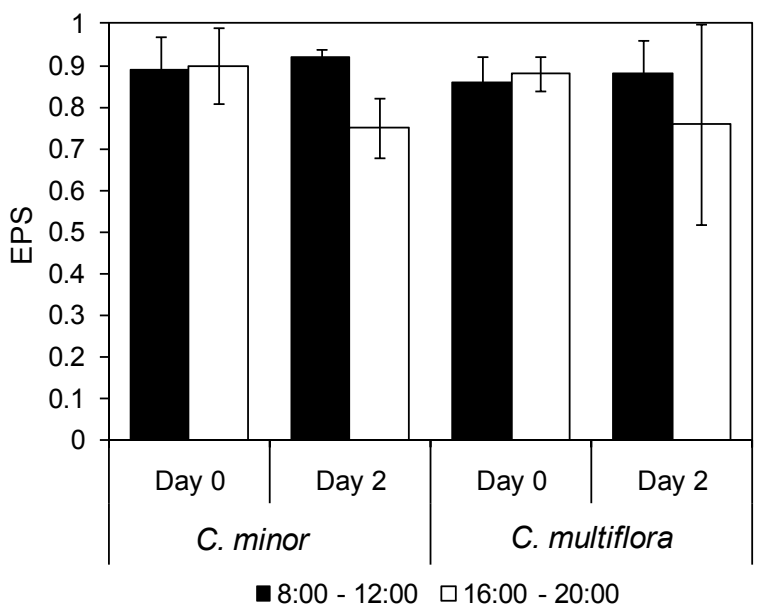

Fig. 3. Daily time course of the level of epoxidation state (EPS) $(\mathrm{V}+0.5 \mathrm{~A}) /(\mathrm{V}+\mathrm{A}+\mathrm{Z})$ of the xanthophyll cycle pigments in leaves of Clusia minor and Clusia multiflora growing at low light (day 0) and during the 2nd day of stress application of high light (HL, 650-740 $\mu \mathrm{mol}$ $\mathrm{m}^{-2} \mathrm{~s}^{-1}$ ) under well-watered conditions. Data represent mean values $\pm \mathrm{SD}(n=3)$. 


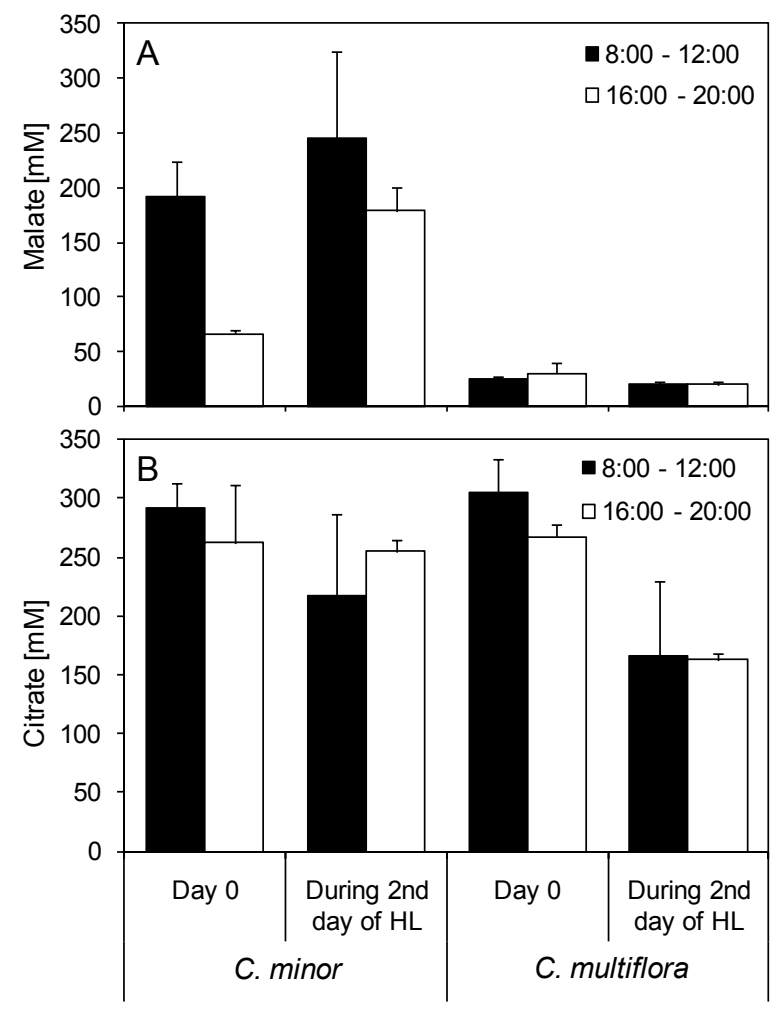

Fig. 4. Daily time course of (A) malate and (B) citrate levels in extracts of leaves of Clusia minor and Clusia multiflora growing at low light (day 0) and during the 2nd day of stress application of high light (HL, $\left.650-740 \mu \mathrm{mol} \mathrm{m} \mathrm{m}^{-2} \mathrm{~s}^{-1}\right)$ under well-watered conditions. Data represent mean values $\pm \operatorname{SD}(n=3)$.

not effective in CAM induction in C. minor, and this paralleled $C$. multiflora.

It is suggested that CAM provides strong protection from photoinhibition during periods of high irradiance (Adams and Osmond, 1988). Some CAM-performing plants are well adapted to strong light (Osmond et al., 1979), and in some CAM plants changes in xanthophyll cycle capacity due to excess light stress have been reported (Lüttge, 2000). In our experiments similar levels of constituents of the xanthophyll cycle were observed in both species (Fig. 2). During the 2nd day of HL treatment independent of the type of carbon metabolism the increases in $\mathrm{A}$ and $\mathrm{Z}$ levels in the afternoon were 2.5-3.8 times the levels observed before noon (8:00-12:00). Thus, the levels of these pigments in the tested plants during the day course responded to stress. While the levels of $\mathrm{V}$ (double epoxide) did not change significantly during the daily time course the increases of A (single epoxide) and Z (no epoxide), which were significant in $C$. minor, indicated deepoxidation in the afternoon under HL in both species, i.e. increased xanthophyll cycle turnover. The changes of $\mathrm{A}$ and $\mathrm{Z}$ levels are not seen in $\mathrm{V}$, because the absolute levels of $\mathrm{V}$ are larger and the changes of $\mathrm{A}$ and $\mathrm{Z}$ levels lie within the range of $\mathrm{SD}$ of the $\mathrm{V}$ level. The small tendency of decrease of the $\mathrm{V}$ level on the 2 nd day parallel to a significant increase of the $\mathrm{A}+\mathrm{Z}$ level can be explained by changes in the total pool of pigments. Thus, HL applied in our experiments was effective in xanthophyll cycle regulation, and low light used before (day 0) was not stressful for both plants.

In our earlier experiments on Clusia plants we were able to show that HL and drought stress induce a significant lowering of the EPS value (Miszalski et al., 2007). The EPS values measured in the present work in both tested plants were comparable before noon and during the afternoon. A decrease in EPS is a characteristic feature for plants exposed to very strong light (Adams and Demmig-Adams, 1992), but HL applied in our measurements (approx. $650-740 \mu \mathrm{mol} \mathrm{m} \mathrm{m}^{-2}$ ) did not affect this parameter. The EPS value (equation in Materials and Methods and Fig. 3) is strongly determined by $\mathrm{V}$ and thus in the present study does not bear out the more subtle changes in $\mathrm{A}$ and $\mathrm{Z}$ levels (Fig. 2). In conclusion we can say that very fast changes and reorganization of PSII as shown by Johnson et al. (2008) and Horton et al. (2005) are not directly connected to CAM-related changes.

CAM plants are able to accumulate high amounts of acids during the night. In CAMperforming $C$. minor plants these fluctuations according to Lüttge (1999) can reach about $200 \mathrm{~mm}$. When comparing malate and citrate fluctuations in our experiments we can state that applied light stress did not increase CAM-characteristic changes (Fig. 4). On the contrary, CAM-characteristic daytime reduction of malate levels observed on day 0 with no HL stress was almost entirely lost (not statistically significant anymore) on day 2 of HL stress. No day/night fluctuations of malate levels, neither at low light nor due to strong light exposure, were observed in C. multiflora. The citrate levels in both species were somehow higher in comparison to the malate levels. Two days of HL stress application caused a decrease of the 
citrate levels in both C. multiflora (statistically significant) and C. minor (not statistically significant), however, without daily fluctuations. All of this indicates that HL stress was not effective in enhancing CAM in C. minor and by contrast even suppressed the CAM activity in the well-watered plants studied, but we can speculate that the used supply of citrate helps to alleviate HL stress.

In addition to this, it is worth to note that day/ night changes in the malate and citrate levels are not parallel. This observation can be compared with results obtained with two obligate CAM species, C. alata and C. hilariana. In these plants, exposed to stress conditions, citrate is decarboxylated during the day later than malate (Kornas et al., 2009). As shown by Lüttge (2007) it can be expected that decarboxylation of malate and citrate are controlled separately. There also was a small tendency of absolute levels of malate in $C$. minor to increase under HL stress (Fig. 4). Thus, we could speculate that light stress stimulates higher malate levels, but no CAM behaviour. A similar tendency was observed in experiments on Mesembryanthemum crystallinum when exposed to a single oxidative stress factor applied as either ozone, $\mathrm{SO}_{2}$, or HL (Niewiadomska et al., 2002; Surówka et al., 2007).

In some experiments with $M$. crystallinum light at the level $600-690 \mu \mathrm{mol} \mathrm{m}^{-2} \mathrm{~s}^{-1}$ induced $\mathrm{C}_{3}$-CAM transformation, but in other experiments strong sunlight $\left(1500 \mu \mathrm{mol} \mathrm{m} \mathrm{m}^{-2} \mathrm{~s}^{-1}\right)$ was not effective in CAM induction (Barker et al., 2004). These results are in accordance with our earlier suggestions pointing out that HL stress as a single stress factor can not be responsible for CAM induction, and that, as indicated by Niewiadomska and Borland (2008), several stress factors are necessary for effective $\mathrm{C}_{3}$-CAM transformation. A similar conclusion can be also drawn from earlier studies on C. minor (Haag-Kerwer et al., 1992). Lüttge (1999) also indicated that C. minor growing at strong light can be found performing $\mathrm{C}_{3}$ metabolism. Moreover, the HL-stress-suppressed CAM activity in the well-watered plants of $C$. minor studied here is consistent with earlier observations where nocturnal $\mathrm{CO}_{2}$ fixation in $C$. minor plants, also well supplied with water, was completely lost when leaves were transferred from 360 to $1200 \mu \mathrm{mol} \mathrm{m}^{-2} \mathrm{~s}^{-1}$ PPFD (Schmitt et al., 1988, note that in this publication the plant studied is wrongly named $C$. rosea rather than $C$. minor).
Both, $\mathrm{C}_{3}$ C. multiflora and $\mathrm{C}_{3}$-CAM C. minor are fully capable of using the xanthophyll cycle for photoprotection. This is now corroborated by the present analysis of $\mathrm{A}$ and $\mathrm{V}$ extending the observations of Herzog et al. (1999) where only Z could be measured. In addition to the xanthophyll cycle $C$. minor can use CAM for photoprotection but obviously does not necessarily need to use it when it is well watered.

We could speculate that in the field it can happen very often that some leaves even in the same crown are exposed to strong light while others are growing in the shade. From an ecological point of view it is easy to understand that light stress alone is not able to induce the very complicated change in the metabolism from $\mathrm{C}_{3}$ to CAM, and plants adapt to this stress using violaxanthin cycle pigment enabling fast, efficient and reversible response. In fact, a study of the transition of $C$. minor from CAM to $\mathrm{C}_{3}$, when water was not limiting and other stresses did not prevail, showed that $\mathrm{C}_{3}$ photosynthesis implies a superior daily photon utilization (Mattos and Lüttge, 2001). Thus, it can be expected that CAM in comparison to $\mathrm{C}_{3}$ should not be induced "that readily". These suggestions also agree with ecophysiological observations reporting that CAM may not be superior to $\mathrm{C}_{3}$ photosynthesis under stressful conditions of high insolation and reduced water supply, as both species occur sympatrically in a light-exposed savanna (Lüttge, 1999). We can suspect that even in some experiments, where strong light was described as single stress factor, this was accompanied by additional stress factors: heat, stomatal closure, low $\mathrm{CO}_{2}$ amount. Thus, HL (above some threshold) would be necessary, but as a single factor is not effective in causing metabolic transformation.

\section{Acknowledgements}

This work was supported by Deutscher Akademischer Austauschdienst (DAAD), Alexander von Humboldt Foundation (AvH), and Polish Comittee for Scientific Research (2685/P01/2006/31). We want to express our gratitude to Prof. Jerzy Kruk for essencial advices connected with this manuscript and we thank Anne Luise Christian for expert technical assistance. 
Adams W. W. and Osmond C. B. (1988), Internal $\mathrm{CO}_{2}$ supply during photosynthesis of sun and shade grown CAM plants in relation to photo-inhibition. Plant Physiol. 86, 117-123.

Adams W. W. and Demmig-Adams B. (1992), Operation of the xanthophylls cycle in higher plants in response to diurnal changes in incident sunlight. Planta 186, 390-398.

Adams W. W. and Demmig-Adams B. (1994), Carotenoid composition and down regulation of photosystem II in three conifer species during the winter. Physiol. Plant. 92, 451-458.

Barker D. H., Marszalek J., Zimpfer J. F., and Adams W. W. (2004), Changes in photosynthetic pigment composition and absorbed energy allocation during salt stress and CAM induction in Mesembryanthemum crystallinum. Funct. Plant Biol. 31, 781-787.

Bartosz G. (1997), Oxidative stress in plants. Acta Physiol. Plant. 19, 47-64.

Borland A. M., Griffiths H., Maxwell C., Fordham M. C., and Broadmeadow M. S. J. (1996), CAM induction in Clusia minor L. during the transition from wet to dry season in Trinidad: the role of organic acid speciation and decarboxylation. Plant Cell Environ. 19, 655-664.

Broetto F., Lüttge U., and Ratajczak R. (2002), Influence of light intensity and salt-treatment on mode of photosynthesis and enzymes of the antioxidative response system of Mesembryanthemum crystallinum. Funct. Plant Biol. 29, 13-23.

Castillo F. (1996), Antioxidative protection in the inducible CAM plant Sedum album L. following the imposition of severe water stress and recovery. Oecologia 107, 469-477.

Chen L.-S., Lin Q., and Nose A. (2002), A comparative study on diurnal changes in metabolite levels in the leaves of three Crassulacean acid metabolism (CAM) species, Ananas comosus, Kalanchö̈ daigremontiana and $K$. pinnata. J. Exp. Bot. 53, 341-350.

Dat J., Vandenabeele S., Vranová E., van Montagu M., Inzé D., and van Breusegem F. (2000), Dual action of active oxygen species during plant stress responses. Cell Mol. Life Sci. 57, 779-795.

Demmig-Adams B. and Adams W. W. (1996), Xanthophyll cycle and light stress in nature: uniform response to excess direct sunlight among higher plant species. Planta 198, 460-470.

Dodd A. N., Griffiths H., Taybi T., Cushman J. C., and Borland A. M. (2002), Integrating diel starch metabolism with the circadian and environmental regulation of Crassulacean acid metabolism in Mesembryanthemum crystallinum. Planta 216, 789-797.

Foyer C. H. and Noctor G. (2003), Redox sensing and signalling associated with reactive oxygen in chloroplasts, peroxisomes and mitochondria. Physiol. Plant. 119, 355-364.

Franco A. C., Ball E., and Lüttge U. (1992), Differential effects of drought and light levels on accumulation of citric and malic acids during CAM in Clusia. Plant Cell Environ. 15, 821-829.

Haag-Kerwer A., Franco A. C., and Lüttge U. (1992), The effect of temperature and light on gas exchange and acid accumulation in the $\mathrm{C}_{3}$-CAM plant Clusia minor L. J. Exp. Bot. 43, 345-352.
Halliwell B. and Gutteridge J. M. C. (1999), Free Radicals in Biology and Medicine. Clarendon Press, Oxford, UK.

Herzog B., Hoffmann S., Hartung W., and Lüttge U. (1999), Comparison of photosynthetic responses of the sympatric tropical C3 species Clusia multiflora $\mathrm{H}$. B. K. and the C3-CAM intermediate species Clusia minor L. to irradiance and drought stress in a phytotron. Plant Biol. 1, 460-470.

Horton P., Wentworth M., and Ruban A. (2005), Control of the light harvesting function of chloroplast membranes: The LHCII-aggregation model for non-photochemical quenching. FEBS Lett. 579, 4201-4206.

Inzé D. and van Montagu M. (1995), Oxidative stress in plants. Curr. Opin. Biotechnol. 6, 153-158.

Johnson M. P., Davison P. A., Ruban A. V., and Horton P. (2008), The xanthophyll cycle pool size controls kinetics of non-photochemical quenching in Arabidopsis thaliana. FEBS Lett. 582, 262-266.

Kornas A., Fischer-Schliebs E., Lüttge U., and Miszalski Z. (2009), Adaptation of the obligate CAM plant Clusia alata to light stress: Metabolic responses. J. Plant Physiol. 166, 1914-1922.

Lüttge U. (1999), One morphotype, three physiotypes: sympatric species of Clusia with obligate $\mathrm{C}_{3}$ photosynthesis, obligate $\mathrm{CAM}$ and $\mathrm{C}_{3}$-CAM intermediate behaviour. Plant Biol. 1, 138-148.

Lüttge U. (2000), Light-stress and Crassulacean acid metabolism. Phyton 40, 65-82.

Lüttge U. (2004), Ecophysiology of Crassulacean acid metabolism (CAM). Ann. Bot. 93, 629-652.

Lüttge U. (2007), Clusia: A Woody Neotropical Genus of Remarkable Plasticity and Diversity. Springer, Berlin, Heidelberg.

Mattos E. A. and Lüttge U. (2001), Chlorophyll fluorescence and organic acid oscillations during transition from CAM to $\mathrm{C}_{3}$-photosynthesis in Clusia minor $\mathrm{L}$. (Clusiaceae). Ann. Bot. 88, 457-463.

Mattos E. A., Herzog B., and Lüttge U. (1999), Chlorophyll fluorescence during CAM-phases in Clusia minor L. under drought stress. J. Exp. Bot. 50, $253-261$.

Miszalski Z., Slesak I., Niewiadomska E., Baczek-Kwinta R., Lüttge U., and Ratajczak R. (1998), Subcellular localization and stress responses of superoxide dismutase isoforms from leaves in the C3-CAM intermediate halophyte Mesembryanthemum crystallinum L. Plant Cell Environ. 21, 169-179.

Miszalski Z., Niewiadomska E., Slesak I., Lüttge U., Kluge M., and Ratajczak R. (2001), The effect of irradiation on carboxylating/decarboxylating enzymes and fumarase activities in Mesembryanthemum crystallinum L., exposed to salinity stress. Plant. Biol. 3, 17-23.

Miszalski Z., Kornas A., Gawronska K., Ślesak I., Niewiadomska E., Kruk J., Christian A. L., FischerSchliebs E., Krish R., and Lüttge U. (2007), Ecophysiological aspects of mitochondrial MnSOD activity in species of Clusia with obligate C3-photosynthesis and $\mathrm{C} 3 / \mathrm{CAM}$ intermediate behaviour. Biol. Plant. 51, $86-92$.

Mittler R. (2002), Oxidative stress, antioxidants and stress tolerance. Trends Plant Sci. 7, 405-410. 
Möllering H. (1974), Malat: Bestimmung mit MalatDehydrogenase und Glutamat-Oxalacetat-Transaminase. In: Methoden der Enzymologie (Bergmeyer H. U., ed.). Academic Press, New York, pp. 1636-1639.

Möllering H. (1985), Citrate. Determination with citrate lyase, $\mathrm{MDH}$ and LDH. In: Methods of Enzymatic Analysis (Bergmeyer H. U., ed.). Academic Press, New York, pp. 2-12.

Niewiadomska E. and Borland A. M. (2008), Crassulacean acid metabolism: a cause or consequence of oxidative stress in planta? In: Progress in Botany 69 (Lüttge U. E., Beyschlag W., and Murata J., eds.). Springer, Berlin, Heidelberg, pp. 247-266.

Niewiadomska E., Miszalski Z., Slesak I., and Ratajczak R. (1999), Catalase activity during $\mathrm{C}_{3}$-CAM transition in Mesembryanthemum crystallinum L. leaves. Free Rad. Res. 31, S251-256.

Niewiadomska E., Pater B., and Miszalski Z. (2002), Does ozone induce a $\mathrm{C}_{3}$-CAM transition in Mesembryanthemum crystallinum leaves? Phyton (Austria) 42, 69-78.

Niewiadomska E., Karpinska B., Romanowska E., Ślesak I., and Karpinski S. (2004), A salinity-induced $\mathrm{C}_{3}$-CAM transition increases energy conservation in the halophyte Mesembryanthemum crystallinum L. Plant Cell Physiol. 45, 789-794.
Osmond C. B., Nott D. L., and Firth P. M. (1979), Carbon assimilation patterns and growth of the introduced CAM plant Opuntia inermis in Eastern Australia. Oecologia 40, 331-350.

Scandalios J. G. (1993), Oxygen stress and superoxide dismutases. Plant Physiol. 101, 7-12.

Schmitt A. K., Lee H. S. J., and Lüttge U. (1988), The response of the $\mathrm{C}_{3}$-CAM tree Clusia rosea to light and water stress. I. Gas exchange characteristics. J. Exp. Bot. 39, 1581-1590.

Siefermann-Harms D. (1987), The light-harvesting and protective functions of carotenoids in photosynthetic membranes. Physiol. Plant. 69, 561-568.

Slesak I., Miszalski Z., Karpinska B., Niewiadomska E., Ratajczak R., and Karpinski S. (2002), Redox control of oxidative stress responses in the $\mathrm{C}_{3}$-CAM intermediate plant Mesembryanthemum crystallinum. Plant Physiol. Biochem. 40, 669-677.

Surówka E., Karolewski P., Niewiadomska E., Libik M., and Miszalski Z. (2007), Antioxidative response of Mesembryanthemum crystallinum plants to exogenous $\mathrm{SO}_{2}$ application. Plant Sci. 172, 76-84.

Thayer S. S. and Björkman O. (1990), Leaf xanthophylls content and composition in sun and shade determinated by HPLC. Photosynth. Res. 23, 331-343. 